\title{
Twenty Years after "Meaningful Differences," It's Time to Reframe the "Deficit" Debate about the Importance of Children's Early Language Experience
}

\author{
Anne Fernald $^{\mathrm{a}} \quad$ Adriana Weisleder $^{\mathrm{b}}$

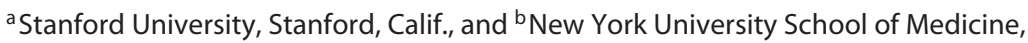 \\ New York, N.Y., USA
}

Fifty years of research have documented a sobering reality: There are substantial differences among parents in how they engage and communicate with their children, and these differences impact the development of a child's language and cognitive skills.

Studies initiated during the War on Poverty first explored how parents' verbal engagement with young children varied among families differing in education and income, or socioeconomic status (SES) [e.g. Bee, Van Egeren, Pytkowicz Streissguth, Nyman, \& Leckie, 1969; Hess \& Shipman, 1965; Schachter, 1979]. In their 1995 monograph Meaningful Differences in the Everyday Experience of Young American Children, Betty Hart and Todd Risley were the first to document huge disparities in the sheer amount of language that caregivers in different families directed to young children. Although they found substantial variability in child-directed speech within as well as between SES groups, the differences between children in advantaged and disadvantaged families were surprisingly large. They also found that those children who did not have the benefits of rich verbal engagement early in life were more likely to be behind in cognitive and language skills in kindergarten and elementary school.

Hart and Risley's [1995] discovery of a 30-million-word gap in language to children from higher- and lower-SES backgrounds over the first three years of life is now widely cited in the popular press as well as in academic journals. But for more than a decade, this powerful study was essentially ignored. In the 1960s, claims that some learning difficulties in children from disadvantaged families could be linked to inadequate cognitive stimulation at home came to be known as the "cultural deficit" model [Riessman, 1962]. A fierce backlash emerged in the 1970s, rejecting this view as unsubstantiated by scientific evidence and as deeply disrespectful of minority parents in poverty whose use of language with children was grounded in cultural traditions of parenting different from those in more affluent mainstream families [Fernald \& Weisleder, 2011]. Consistent with these criticisms, a dominant view in the field of language acquisition through the 1990s was that focusing on SES differences in speech

\footnotetext{
KARGER 125/\% ๑ 2015 S. Karger AG, Basel

E-Mail karger@karger.com www.karger.com/hde
}

Anne Fernald

Jordan Hall, Building 420, Room 202

Stanford University, 450 Serra Mall

Stanford, CA 94305 (USA)

E-Mail afernald@stanford.edu 
to children reflected a "deficit approach to the language of disadvantaged subcultures, providing the middle-class researcher with yet another stick with which to beat the working-class parent" [Pine, 1992, p. 247]. That Hart and Risley were not cited at all in the hefty recent Handbook of Language Socialization [Duranti, Ochs, \& Schieffelin, 2012] shows that their results are still viewed by some scholars as irrelevant to understanding how language is learned.

But fortunately, these perspectives are starting to change. Claims that early interactions between parents and infants lay the foundation for children's later language and cognitive development are no longer dismissed as scientifically questionable and culturally disrespectful. Several researchers have now studied larger samples of families from more diverse backgrounds, confirming disparities among children in their early language experience that are related to several different aspects of vocabulary and language growth [Hoff, 2003, 2013; Huttenlocher, Waterfall, Vasilyeva, Vevea, \& Hedges, 2010; Pan, Rowe, Singer, \& Snow, 2005; Rowe, 2012; Song, Spier, \& Tamis-LeMonda, 2014]. Our own research has shown that by 24 months of age, English-learning children from lower-SES Caucasian families were already 6 months behind their more advantaged peers in vocabulary and language understanding [Fernald, Marchman, \& Weisleder, 2013]. In another study with Spanish-learning toddlers from Latino families, we recorded parent-child interactions over a 10-hour day at home. There were surprisingly large differences in how much parents talked to their 18-month-olds even within this low-income population. One toddler heard 1,200 words of child-directed speech per hour, while another heard only 67 words per hour. Importantly, the amount of language these Latino children heard at home at 18 months predicted their vocabulary and language understanding skills six months later. Moreover, it was speech addressed directly to the child - not the overall amount of speech overheard by the child from adult-to-adult conversations or on TV - that predicted language outcomes [Weisleder \& Fernald, 2013].

Although the "30-million-word gap" has become a popular buzzword in recent discussions of early childhood interventions and policy [e.g. Talbot, 2015], Hart and Risley were explicit that the quantity of speech is actually a proxy for the quality of children's early language experience. Quantity and quality of child-directed speech are highly correlated in real world interactions. Parents who talk more with their children also tend to use more of the rich vocabulary, complex ideas, and back-andforth conversation known to promote language growth [Rowe, 2012]. It is this kind of high-quality verbal engagement that current policy initiatives are trying to encourage.

While many studies find differences in parenting practices between families in different SES groups, it is important to emphasize that parents' verbal engagement with children also varies within these groups. Hart and Risley [1995] found that families with higher incomes and education tend to talk more with their children than do those from lower SES levels, but they also found that some working-class families talked with their children as much as professionals, and some affluent families talked as little as those in poverty. More recent studies have found exactly the same pattern with both English- and Spanish-speaking families from different SES groups [Hoff, 2003; Huttenlocher et al., 2010; Weisleder, Otero, Marchman, \& Fernald, 2015]. The good news here is that parents' verbal engagement with their infant is often a better predictor of that child's developing language proficiency than is family SES [Hoff, 2003; Weisleder et al., 2015]. 
This new research on the critical role of early language experience in infancy resonates with stunning developments in the fields of pediatrics, psychobiology, and epigenetics showing how poverty-related disparities in other aspects of early experience can have cascading effects with enduring developmental consequences. The debilitating conditions of poverty are particularly damaging for infants and young children, whose bodies and brains are still actively under construction. Many studies using biological measures have revealed how the developing physiology and neural circuitry of the young child are vulnerable to effects of undernutrition, stress, and instability in the first years of life, which can inhibit the development of physical and mental capacities throughout adulthood [Shonkoff et al., 2012]. As with physical undernutrition, lack of "mental nutrition" can also compromise the developing brain, with lasting consequences for children's ability to build the skills they will need to flourish in school and later life.

Critics of the simplistic deficit reasoning of the 1960s raised legitimate concerns about not "blaming parents" for their children's lack of readiness for school and the importance of respecting differences among cultures in ways of interacting with children. But while it is important to recognize that many conditions associated with poverty shape children's experiences and development, to ignore the role of parents is to dismiss a vital influence in children's lives. Since the science is now clear that engagement in rich verbal interactions with adults is critical for children's success in school, sharing this information with parents - who all want to help their children succeed - is not a form of blame but a form of empowerment.

The more our society understands how critical it is to nourish a young child's mind starting at birth, the more we all stand to benefit. We applaud initiatives that open the door to conversations about how to encourage quality in parent-child interactions, how to build more supportive communities, and how our society can play a stronger role in supporting child development.

\section{References}

Bee, H.L., Van Egeren, L.F., Pytkowicz Streissguth, A., Nyman, B.A., \& Leckie, M.S. (1969). Social class differences in maternal teaching strategies and speech patterns. Developmental Psychology, 1, 726734.

Duranti, A., Ochs, E., \& Schieffelin, B.B. (2012). The handbook of language socialization. Oxford, England: Wiley-Blackwell.

Fernald, A., Marchman, V.A., \& Weisleder, A. (2013). SES differences in language processing skill and vocabulary are evident at 18 months. Developmental Science, 16, 234-248.

Fernald, A., \& Weisleder, A. (2011). Early language experience is vital to developing fluency in understanding. In S.B. Neuman \& D.K. Dickinson (Eds.), Handbook of early literacy research. Vol. 3 (pp. 3-19). New York, NY: Guilford Press.

Hart, B., \& Risley, T.R. (1995). Meaningful differences in the everyday experience of young American children. Baltimore, MD: Brookes.

Hess, R.D., \& Shipman, V.C. (1965). Early experience and the socialization of cognitive modes in children. Child Development, 36, 869-886.

Hoff, E. (2003). The specificity of environmental influence: Socioeconomic status affects early vocabulary development via maternal speech. Child Development, 74, 1368-1378.

Hoff, E. (2013). Interpreting the early language trajectories of children from low-SES and language minority homes: Implications for closing achievement gaps. Developmental Psychology, 49, 4-14.

Huttenlocher, J., Waterfall, H., Vasilyeva, M., Vevea, J., \& Hedges, L.V. (2010). Sources of variability in children's language growth. Cognitive Psychology, 61, 343-365. 
Pan, B.A., Rowe, M.L., Singer, J.D., \& Snow, C.E. (2005). Maternal correlates of growth in toddler vocabulary production in low-income families. Child Development, 76, 763-782.

Pine, J.M. (1992). Commentary on: How should frequency in input be measured? by E. Hoff-Ginsberg. First Language, 12, 245-249.

Riessman, F. (1962). The culturally deprived child. New York, NY: Harper \& Row.

Rowe, M.L. (2012). A longitudinal investigation of the role of quantity and quality of child-directed speech in vocabulary development. Child Development, 83, 1762-1774.

Schachter, F.F. (1979). Everyday mother talk to toddlers: Early intervention. New York, NY: Academic Press.

Shonkoff, J.P., Garner, A.S., and the Committee on Psychosocial Aspects of Child and Family Health, Committee on Early Childhood, Adoption, and Dependent Care, and Section on Developmental and Behavioral Pediatrics (2012). The lifelong effects of early childhood adversity and toxic stress. Pediatrics, 129, e232-e246.

Song, L., Spier, E.T., \& Tamis-LeMonda, C.S. (2014). Reciprocal influences between maternal language and children's language and cognitive development in low-income families. Journal of Child Language, 41, 305-326.

Talbot, M. (2015, January 12). The talking cure. The New Yorker. Retrieved from http://www.newyorker. com.

Weisleder, A., \& Fernald, A. (2013). Talking to children matters: Early language experience strengthens processing and builds vocabulary. Psychological Science, 24, 2143-2152.

Weisleder, A., Otero, N., Marchman, V.A., \& Fernald, A. (March, 2015). Child-directed speech mediates SES differences in language-processing skill and vocabulary in Spanish-learning children. Presented at the Biennial Meeting of the Society for Research in Child Development, Philadelphia, PA. 